\title{
O QUE DIZEM OS ESTUDOS SOBRE A FORMAÇÃO DO EN- FERMEIRO DOCENTE?
}

\author{
WHAT DO STUDIES SAY ON THE TRAINING OF THE NURSE TEACHER? \\ ¿QUÉ DICEN LOS ESTUDIOS SOBRE LA FORMACIÓN DEL ENFERMERO DO- \\ CENTE?
}

\author{
Roberlandia Evangelista Lopes \\ Enfermeira. Graduada pela Universidade Estadual Vale do Acaraú. \\ Ms. em Saúde da Família pela Universidade Federal do Ceará \\ Doutoranda em Educação pela Universidade Estadual do Ceará - UECE, Bolsista CNPQ. \\ roberlandialopes@hotmail.com \\ Silvia Maria Nobrega Therrien \\ Enfermeira. Doutora em Sociologia pela Universidade de Salamanca, Espanha. \\ Pós-Doutorado em educação pela Universidade de Valencia, Espanha. \\ Professora do curso de Medicina e do mestrado e Doutorado Acadêmico em Educação da Universidade Estadual do Ceará - UECE. \\ Pesquisadora $\mathrm{PQ}$ do CNPq. \\ silnth@terra.com.br
}

RESUMO: A identificação das evidências científicas disponíveis na literatura que abordem a formação do enfermeiro docente é discutida neste artigo. Trata-se de uma revisão integrativa da literatura realizada na base de dados LILACS, MEDLINE, IBSCS COCHRANE e SCIELO, BDENF e CAPES, a partir dos descritores: "formação"; "enfermeiro"; "enfermagem"; "docência"; "estudo atemporal". Foram identificados 3388, dessas restaram n = 28. Emergiram três categorias temáticas: práticas pedagógicas do enfermeiro, obstáculos didáticos, formação inicial e formação continuada. Na categoria práticas pedagógicas do enfermeiro, percebe-se a necessidade dos enfermeiros docentes melhorarem sua prática pedagógica; três artigos apontam para a necessidade de uma prática reflexiva e/ou possível processo formativo e ação pedagógica transformadora; quatro propostas relatam metodologias ativas, das quais, referencia-se o Arco de Charles Maguerez, assim como a menção de autores que trabalham à luz de uma prática pedagógica emancipadora; na categoria obstáculos didáticos, encontramos cinco produções que discutem desde uma formação excessivamente técnica, ausência de recursos, a falta de preparação específica para aproximação da práxis. A categoria formação inicial e formação continuada, revela que todas as produções textuais apontaram para a temática formação inicial e continuada do docente enfermeiro; destas, dez produções deram destaque às competências e habilidades requeridas para um futuro docente na área. $\mathrm{O}$ estudo sinaliza para a necessidade de formação, seja inicial e/ou continuada, voltada ao enfermeiro docente; de uma formação reflexiva, dotada de questionamentos, argumentações científicas, com espaços de liberdade, a fim de proporcionar autonomia aos sujeitos.

PALAVRAS-CHAVE: Formação. Enfermeiro. Enfermagem. Docência. Ensino Superior.

ABSTRACT: The identification of the scientific evidence available in literature about the formation of nurse faculty is discussed in this article.This is an integrative literature review conducted in the LILACS, MEDLINE, IBSCS COCHRANE, SCIELO, BDENF and CAPES databases, the keywords used were "training"; "nurse"; "nursing"; "teaching"; "atemporal study". We identified 3,388 studies, from which 28 were included $(n=28)$. Three thematic categories emerged: pedagogical practices of the nurse, textbook obstacles, and basic and continued training. In the category of pedagogical practices of the nurse, we noticed the need for nurse teachers to improve their pedagogical practice; three studies point out the need for reflexive practice and/or possible training process focus, and transformative pedagogical action; four proposals report active methods, of which, the Charles Maguerez Arc is referenced, as also with mention to the authors that worked in light of emancipating pedagogical practice; in the textbook obstacle category, we found five studies that discuss from excessive technical training, lack of resources, to the lack of specific preparation for praxis approach. The category of basic and continued training, reveals that all textual production points to the basic and continued training theme of the nurse teacher; of which, ten studies highlighted the competences and abilities required for a teaching future in the area. The study signals for the need of training, being either basic and/or continued, directed towards the nurse teacher; in reflexive training, endowed with questionings, scientific reasoning, and freedom, in order to provide them autonomy.

KEYWORDS: TTraining. Nurse. Nursing. Teaching. Higher Education.

$\overline{\text { Artigo recebido em maio de } 2014}$

Aprovado em julho de 2014

Cad. Pes., São Luís, v. 21, n. 2, mai./ago. 2014 
RESUMEN: Identificar las evidencias científicas disponibles en la literatura que aborden la formación del enfermero docente. Se trata de una revisión integradora de la literatura realizada en la base de datos LILACS, MEDLINE, IBSCS COCHRANE y SCIELO, BDENF y CAPES, desde los descriptores: "formación"; "enfermero"; "enfermería"; "docencia"; "estudio atemporal". Fueron identificados 3388, de éstas restaron $n=28$. Emergieron tres categorías temáticas: prácticas pedagógicas del enfermero, obstáculos didácticos y formación inicial y formación continuada. En la categoría prácticas pedagógicas del enfermero, se da cuenta de la necesidad de los enfermeros docentes mejorar su práctica pedagógica; tres artículos apuntan para la necesidad de una práctica reflexiva y/o posible proceso formativo y acción pedagógica transformadora; cuatro propuestas informan metodologías activas, las cuales, se referencian el Arco de Charles Maguerez, así con la mención de autores que trabajan a la luz de una práctica pedagógica emancipadora; en la categoría obstáculos didácticos, encontramos cinco producciones que discuten desde una formación excesivamente técnica, escasos recursos, falta de preparo específico para aproximación de la praxis. Ya la categoría formación inicial y formación continuada, revelan que todas las producciones textuales apuntaron para la temática formación inicial y continuada del docente enfermero; de éstas, diez producciones han puesto de manifiesto las habilidades requeridas para un futuro docente en el área. El estudio señala la necesidad de formación, sea inicial y/o continuada, centrada en el enfermero docente; de una formación reflexiva, dotada de cuestionamientos, argumentos científicas, con espacios de libertad, a fin de proporcionar autonomía a los sujetos. PALABRAS CLAVE: Formación. Enfermero. Enfermería. Docencia. Enseñanza Superior. 
O QUE DIZEM OS ESTUDOS | Roberlandia Evangelista Lopes e Silvia Maria Nobrega Therrien

\section{1 | Introdução}

O mundo acadêmico, especialmente a formação docente, nunca esteve tão em evidência quanto nos últimos anos, constituindo-se alvo de inúmeros questionamentos que, entre outros aspectos, incidem sobre os desafios da contemporaneidade que exigem uma 'outra' formação que se proponha a conseguir respostas exitosas. Na Enfermagem observamos que a formação esteve predominantemente articulada ao 'mundo' do trabalho, uma preocupação manifestada na década de 1960, sob iniciativa da Associação Brasileira de Enfermagem (ABEn). Atualmente se evidencia uma possibilidade de condução dessa formação, preocupada com o desafio contemporâneo do setor educacional, que é o de formar cidadãos competentes na aplicação prática dos saberes, na capacidade de compreender e se enquadrar no mundo. Entendemos que é nesse contexto que encontramos o campo de estudos sobre a formação da enfermeira, e essa lógica como uma das mais adequadas a responder aos desafios da educação no século XXI.

Como a enfermeira está sendo formada e como constrói ativamente diferentes intervenções e mediações na realização de seu trabalho na atualidade, são evidências que contribuem para se estruturar e conduzir a sua formação, bem como dá margem a um campo de estudos e discussões que culminam com o início de algumas compreensões, entre elas, a concepção da enfermeira como profissional, como sujeito reflexivo, além da constatação de que, no exercício dessa profissão, a reflexão-na-ação e sobre a ação, parece ser um componente bastante significativo e também definidor de respostas adequadas aos cenários de trabalho em contínuas mudanças e exigências de uma formação que ensine a pensar, afirma Nóbrega-Therrien (2001). Entretanto, indaga-se: há efetivação deste processo descrito?

Demo (2002) afirma que a formação da enfermeira, e mais especificamente a formação do enfermeiro docente, deve estar envolvida sistematicamente em atividades de pesquisa que favoreçam o desenvolvimento de racionalidades que dão suporte a práticas reflexivas geradoras de questionamentos e argumentações científicas, as quais tendem a moldar os saberes objetos de ensino, proporcionando aprendizagens mais significativas e autônomas para os sujeitos aprendizes. Acompanhando esse raciocínio, existe a necessidade, portanto, de conhecer como e em que princípios e compreensões estão se discutindo essa formação, no âmbito do que se tem produzido e publicado sobre essa profissão pelos que a investigam. Dito isso, o estudo ora apresentado tem como objetivo identificar as evidências científicas disponíveis na literatura que abordem a formação do enfermeiro docente.

\section{2 | CAMINHO METODOLÓGICO}

Para o alcance do objetivo proposto, selecionou-se o método de revisão integrativa. Com base em estudos internacionais, Mendes, Silveira e Galvão (2008) dizem que este tem seis etapas: identificação do tema e seleção da hipótese para posteriormente estabelecer critérios para inclusão e exclusão de estudos; amostragem ou busca na literatura; definição das informações a serem extraídas dos estudos selecionados; avaliação dos estudos incluídos na revisão; interpretação dos resultados; e apresentação da revisão.

A questão norteadora foi: Como a literatura vem abordando a formação do enfermeiro docente? Para o levantamento e análise da produção bibliográfica realizou-se a busca de estudos nas bases de dados Literatura Latino-Americana e do Caribe em Ciências da Saúde (LILACS), Medical Literature Analysis and Retrieval System On-Line (MEDLINE), (IBSCS), (COCHRANE) e SCIELO; bases de dados de Enfermagem (BDENF) e o portal da Coordenação de Aperfeiçoamento de Pessoal de Ensino Superior (CAPES). 
Os descritores selecionados na busca foram: professor, docência, enfermeiro e formação, associados pelo operador booleano and. Isso permitiu realizar as seguintes associações: enfermeiro docente/professor; formação na docência e formação na enfermagem. Optou-se por incluir estudos que apresentassem a formação do enfermeiro docente, apresentado na língua portuguesa, espanhol e inglês, assim como texto completo e disponível de forma online, sem temporalidade demarcada. Ressalta-se que o levantamento das publicações nas bases de dados ocorreu entre os meses de fevereiro a março de 2014.

Ao utilizar os descritores encontramos 3388 (três mil trezentos e oitenta e oito) produções textuais. O processo de procura dos artigos se deu dessa forma: BVS (LILACS, MEDLINE, IBSCS COCHRANE e SCIELO) com os descritores enfermeiro docente/professor encontramos 1340 (mil trezentos e quarenta) publicações; com os descritores formação na docência, encontramos 140 (cento e quarenta) produções. Na base de dados da CAPES encontramos, respectivamente, enfermeiro docente/professor, 74 (setenta e quatro) produções; e formação na docência, 552 (quinhentos e cinquenta e duas) produções; enfermeiro professor, 121 (cento e vinte um). Na base de dados da BDEnf, obtivemos os seguintes achados com os descritores enfermeiro docente/ professor, 99 (noventa e nove) artigos; com formação na docência 25 (vinte e cinco) artigos; e, por fim, com os descritores formação na enfermagem, 1037 (mil e trinta e sete) artigos, optou-se por acrescentar esse descritor nessa base, por ela tratar de produções específicas da categoria pesquisada.

Refinando, de acordo com os critérios de inclusão, foram selecionadas pelo título e leitura dos resumos as seguintes produções textuais, de acordo com cada base de dados: BDenf: 24 (vinte e quatro), BVS (LILACS, MEDLINE, IBSCS COCHRANE e SCIELO): 18 (dezoito), entretanto, 16(dezesseis) se repetiam entre as bases da BDenf, perfazendo apenas 2 (dois) artigos distintos; e CAPES: 8 (oito), ressalta-se que, destes, apenas 2 (dois) não se repetiram nas bases anteriores. Destaca-se que, para a inclusão, foi considerado o artigo encontrado na base de dados de maior produção, ou seja, BDenf. Em suma, 28 produções textuais constituíram a amostra do estudo. Foi elaborado um instrumento de coleta de informações que gerou a caracterização do estudo: título, nome do periódico/tipo de produção, ano de publicação, objetivo e categorias de análise. Para a realização da análise, optou-se pelo uso da técnica textual qualitativa. Ressalta-se o cumprimento dos princípios da ética.

\section{3 | RESULTADOS DOS ESTUDOS LEVANTADOS: o que dizem os estudos sobre a formação da enfermeira}

Nesta revisão integrativa, obtiveram-se os seguintes artigos que se encontram no quadro 1, 2 e 3.

Quadro 1 - Distribuição dos artigos localizados nas bases de dados, LILACS, MEDLINE, IBSCS COCHRANE e SCIELO, BDENF e CAPES sobre formação do enfermeiro docente, segundo o periódico publicado/tipo de produção científica, título e ano. Fortaleza, Ceará, Brasil, 2014.

\begin{tabular}{|l|l|l|l|}
\hline$N^{0}$ & $\begin{array}{l}\text { Periódico ou tipo de } \\
\text { produção científica }\end{array}$ & \multicolumn{1}{|c|}{ Título } & Ano \\
\hline 1 & $\begin{array}{l}\text { Revista Brasileira de } \\
\text { enfermagem }\end{array}$ & $\begin{array}{l}\text { Obstáculos didáticos no cotidiano da prática } \\
\text { pedagógica do enfermeiro professor }\end{array}$ & 1986 \\
\hline 2 & Dissertação & $\begin{array}{l}\text { Reflexão sobre a prática educativa dos enfer- } \\
\text { meiros assistenciais na formação profissional }\end{array}$ & 2002 \\
\hline
\end{tabular}


O QUE DIZEM OS ESTUDOS | Roberlandia Evangelista Lopes e Silvia Maria Nobrega Therrien

\begin{tabular}{|l|l|l|l|}
\hline 3 & Dissertação & $\begin{array}{l}\text { Prática pedagógica na educação profissional } \\
\text { de enfermagem - expressões autocríticas de } \\
\text { um grupo de enfermeiras (os) educadoras (es) }\end{array}$ & 2002 \\
\hline 4 & $\begin{array}{l}\text { Revista Latino ameri- } \\
\text { cana de enfermagem }\end{array}$ & $\begin{array}{l}\text { Refletindo sobre o aprendizado do papel de } \\
\text { educador no processo de formação do enfer- } \\
\text { meiro }\end{array}$ & 2004 \\
\hline 5 & Dissertação & $\begin{array}{l}\text { A identidade profissional do enfermeiro profes- } \\
\text { sor do ensino técnico em enfermagem }\end{array}$ & 2004 \\
\hline 6 & $\begin{array}{l}\text { Rev Latino-am Enfer- } \\
\text { magem }\end{array}$ & $\begin{array}{l}\text { A educação para o século XXI e a formação do } \\
\text { professor reflexivo na enfermagem }\end{array}$ & 2004 \\
\hline 7 & R Enferm UERJ & $\begin{array}{l}\text { Perfil dos professores de ensino médio profis- } \\
\text { sionalizante em Enfermagem }\end{array}$ & 2005 \\
\hline 8 & $\begin{array}{l}\text { Revista Brasileira de } \\
\text { enfermagem }\end{array}$ & $\begin{array}{l}\text { Formação do enfermeiro: características } \\
\text { do professor e o sucesso escolar }\end{array}$ & 2006 \\
\hline 9 & $\begin{array}{l}\text { Rev Bras Enferm } \\
\text { Formação de formadores: a prática educativa } \\
\text { de um programa de pós-graduação em enfer- } \\
\text { magem }\end{array}$ & 2006 \\
\hline 10 & $\begin{array}{l}\text { Revista Brasileira de } \\
\text { enfermagem }\end{array}$ & $\begin{array}{l}\text { Enfermeiro professor: um diálogo com a for- } \\
\text { mação pedagógica }\end{array}$ & 2007 \\
\hline
\end{tabular}

Fonte: LILACS, MEDLINE, IBSCS COCHRANE e SCIELO, BDENF e CAPES.

Quadro 2 - Distribuição dos artigos/produções científicas localizados nas bases de dados, LILACS, MEDLINE, IBSCS COCHRANE e SCIELO, BDENF e CAPES, sobre formação do enfermeiro docente, segundo o periódico publicado/tipo de produção científica, título e ano. Fortaleza, Ceará, Brasil, 2014.

\begin{tabular}{|c|l|l|l|}
\hline$N^{\circ}$ & $\begin{array}{l}\text { Periódico ou tipo de } \\
\text { produção científica }\end{array}$ & \multicolumn{1}{|c|}{ Título } & Ano \\
\hline 11 & Rev Esc Enferm USP & $\begin{array}{l}\text { Reflexões sobre o preparo para a docência } \\
\text { na pós-graduação em enfermagem }\end{array}$ & 2007 \\
\hline 12 & Dissertação & $\begin{array}{l}\text { Competências para ação educativa da enfer- } \\
\text { meira: uma interface entre o ensino e a as- } \\
\text { sistência de enfermagem }\end{array}$ & 2007 \\
\hline 13 & $\begin{array}{l}\text { Escola Ana Nery de } \\
\text { enfermagem }\end{array}$ & $\begin{array}{l}\text { Alternativas para a prática docente no } \\
\text { ensino superior de enfermagem }\end{array}$ & 2007 \\
\hline 14 & Rev Esc Enferm USP & $\begin{array}{l}\text { Reflexões sobre competência docente no ensi- } \\
\text { no de enfermagem }\end{array}$ & 2007 \\
\hline 15 & $\begin{array}{l}\text { Revista Brasileira de } \\
\text { enfermagem }\end{array}$ & $\begin{array}{l}\text { Os reflexos da formação inicial na atuação dos } \\
\text { professores enfermeiros }\end{array}$ & 2008 \\
\hline 16 & Rev. enferm. UERJ & $\begin{array}{l}\text { Um olhar sobre a formação do enfermeiro/do- } \\
\text { cente no Brasil }\end{array}$ & 2008 \\
\hline 17 & Rev Esc Enferm USP & $\begin{array}{l}\text { Percepção dos enfermeiros sobre a avaliação } \\
\text { da aprendizagem nos treinamentos desen- } \\
\text { volvidos em um hospital de São Paulo }\end{array}$ & 2008 \\
\hline
\end{tabular}


O QUE DIZEM OS ESTUDOS | Roberlandia Evangelista Lopes e Silvia Maria Nobrega Therrien

\begin{tabular}{|l|l|l|l|}
\hline 18 & $\begin{array}{l}\text { Cuidar arte enferma- } \\
\text { gem }\end{array}$ & $\begin{array}{l}\text { Currículo de enfermagem: competências e ha- } \\
\text { bilidades para formação de docentes }\end{array}$ & 2009 \\
\hline 19 & $\begin{array}{l}\text { Revista Iberoameri- } \\
\text { cana de Educación }\end{array}$ & $\begin{array}{l}\text { Da formação por competências à prática do- } \\
\text { cente reflexiva }\end{array}$ & 2009 \\
\hline 20 & Cienc Cuid Saude & $\begin{array}{l}\text { Identificação de novas práticas pedagógicas } \\
\text { na percepção dos docentes de um curso de } \\
\text { enfermagem }\end{array}$ & 2010 \\
\hline
\end{tabular}

Fonte: LILACS, MEDLINE, IBSCS COCHRANE e SCIELO, BDENF e CAPES.

Quadro 3 - Distribuição dos artigos/produção científica localizados nas bases de dados, LILACS, MEDLINE, IBSCS COCHRANE e SCIELO, BDENF e CAPES, sobre formação do enfermeiro docente, segundo o periódico publicado/tipo de produção científica, título e ano. Fortaleza, Ceará, Brasil, 2014

\begin{tabular}{|l|l|l|l|}
\hline $\mathbf{N}^{\mathbf{0}}$ & $\begin{array}{l}\text { Periódico ou tipo de } \\
\text { produção científica }\end{array}$ & \multicolumn{1}{|c|}{ Título } & Ano \\
\hline 21 & Rev Bras Enferm & $\begin{array}{l}\text { Repensando o ser enfermeiro docente na per- } \\
\text { spectiva do pensamento complexo }\end{array}$ & 2010 \\
\hline 22 & Interscienceplace & $\begin{array}{l}\text { Ensino por competências em enfermagem: in- } \\
\text { terpretações e práticas pedagógicas }\end{array}$ & 2010 \\
\hline 23 & Rev Bras Enferm & $\begin{array}{l}\text { Formação de mestres em enfermagem na } \\
\text { Universidade Federal de Santa Catarina: con- } \\
\text { tribuições sob a ótica de egressos }\end{array}$ & 2010 \\
\hline 24 & Rev Esc Enferm USP & $\begin{array}{l}\text { Práticas pedagógicas no ensino de enferma- } \\
\text { gem: um estudo na perspectiva da análise in- } \\
\text { stitucional }\end{array}$ & 2010 \\
\hline 25 & $\begin{array}{l}\text { Rev. Latino-Am. En- } \\
\text { fermagem }\end{array}$ & $\begin{array}{l}\text { Processo de construção do conhecimento } \\
\text { pedagógico do docente universitário de enfer- } \\
\text { magem }\end{array}$ & 2011 \\
\hline 26 & Rev Gaúcha Enferm. & $\begin{array}{l}\text { Licenciatura e bacharelado em enfermagem: } \\
\text { experiências e expectativas de estudantes }\end{array}$ & 2011 \\
\hline 27 & Esc Anna Nery & $\begin{array}{l}\text { Arco de Charles Maguerez: refletindo estraté- } \\
\text { gias de metodologia ativa na formação de } \\
\text { profissionais de saúde }\end{array}$ & 2012 \\
\hline 28 & Enfermagem em Foco & $\begin{array}{l}\text { Estágio de docência na formação do mestre } \\
\text { em enfermagem: relato de experiência }\end{array}$ & 2012 \\
\hline
\end{tabular}

Fonte: LILACS, MEDLINE, IBSCS COCHRANE e SCIELO, BDENF e CAPES.

Entre os periódicos, destacaram-se a revista brasileira de enfermagem (sete artigos) e a Revista escola de enfermagem USP (quatro artigos). No que condiz a outro de tipo de apresentação da produção textual, obteve-se mais dissertações (quatro). Quanto ao ano de publicação, destaca-se a produção mais antiga, 1986 (uma) e 2010 (cinco). Quanto aos objetivos propostos, destaca-se que 19 (dezenove) dos estudos abordaram enfoque nas práticas/formação pedagógicas do en- 
fermeiro docente e em atender as novas demandas da prática docente. Um (1) artigo trouxe para discussão os obstáculos didáticos da prática pedagógica do enfermeiro docente; três (3) artigos traçaram o perfil enfermeiro docentes; outras duas (2) produções textuais relataram vivência de metodologias de ensino que corroboram com a formação do docente enfermeiro; três (3) publicações se reportaram a retratar perspectivas, experiências e percepções do enfermeiro docente. Acompanhe nos quadros 1, 2 e 3.

As categorias de análise construídas foram resultantes do maior enfoque atribuído pelos autores das produções analisadas, conforme apresentado no Quadro 4. Essas serão mencionadas de acordo com a numeração atribuída nos quadros 1, 2 e 3 para nortear e situar a discussão.

Quadro 4 - Categorias de Análise sobre a formação do enfermeiro docente dos artigos/produções científicas localizados nas bases de dados, LILACS, MEDLINE, IBSCS COCHRANE e SCIELO, BDENF e CAPES, Fortaleza, Ceará, Brasil, 2014

\begin{tabular}{|l|l|}
\hline Categorias de análise & Identificação dos artigos \\
\hline Obstáculos didáticos & $1,7,15,17$ e 21 \\
\hline Prática pedagógica do enfermeiro. & $1,2,3,5,6,8,9,10,12,14,15,18,19,20,22,24$ \\
& e 27. \\
\hline Formação Inicial e Formação continuada & $\begin{array}{l}1,2,3,4,5,6,7,8,9,10,11,12,13,14,15,16, \\
17,18,19,2021,22,23,24,25,26 \text { e }, 28 .\end{array}$ \\
\hline
\end{tabular}

Fonte: LILACS, MEDLINE, IBSCS COCHRANE e SCIELO, BDENF e CAPES.

\section{4 | DISCUSSÃO SOBRE OS ACHADOS}

\subsection{Obstáculos didáticos}

Rodrigues e M. Sobrinho (2008), utilizando as narrativas agruparam os obstáculos em três subcategorias, que constituem as condições causais dos obstáculos, assim denominadas: obstáculos didáticos e o professor, obstáculos didáticos e o aluno, e obstáculos didáticos e a instituição. 0 artigo 1 e 15 ressaltam que houve lacuna na preparação específica para o exercício da docência pelo enfermeiro, prática pedagógica sustentada pela dicotomia teoria-prática, trabalho didático com disciplinas das quais não têm domínio de conteúdo. E, no artigo 15, encontramos a seguinte informação: 37,50\% dos enfermeiros afirmam ter formação técnica, sem preparo para a docência.

No artigo 21, são descritas algumas dificuldades relatadas pelos docentes enfermeiros, dentre elas temos: Atitude defensiva dos docentes face às críticas dos alunos; dificuldade estratégica no modo de fazer o link com alguns assuntos transversais (exemplo: políticas públicas, ética profissional, situações práticas); ansiedade em vencer os conteúdos programáticos (quantidade de conteúdos em detrimento da qualidade do ensino); dificuldades em promover aulas mais atrativas, dinâmicas e construtivas (capacidade didática do professor); dificuldade para lidar com as singula-

ridades/individualidades dos estudantes; postura docente tradicional (aulas centradas no professor) e deficiência de liderança, por parte de alguns professores, para promover participação ativa dos alunos, bem como a integração teoria-prática.

Dentre os obstáculos relacionados aos alunos, os enfermeiros professores da UESPI destacaram a deficiência na base teórica, o ingresso na universidade cada vez mais cedo, ou seja, a imaturidade, e a falta de preparo para lidar com a mudança da prática pedagógica do professor. (RODRIGUES; M. SOBRINHO, 2008, p. 438). 
Em relação à instituição, foi constatado que as condições deficientes de recursos, estrutura, campo de estágio e baixos salários estabelecem limites para o bom desempenho do trabalho do professor. No artigo 7, verifica-se que as contradições do mercado de trabalho e as instituições educacionais têm provocado distorções no exercício da docência, quando autorizam o enfermeiro a ministrar aulas, mesmo sem formação pedagógica.

Em relação à instituição, foi constatado que as condições deficientes de recursos, estrutura, campo de estágio e baixos salários estabelecem limites para o bom desempenho do trabalho do professor. No artigo 7, verifica-se que as contradições do mercado de trabalho e as instituições educacionais têm provocado distorções no exercício da docência, quando autorizam o enfermeiro a ministrar aulas, mesmo sem formação pedagógica.

No artigo 17, há um apontamento para percepção dos enfermeiros sobre a avaliação da aprendizagem nos treinamentos. Os resultados da pesquisa de Astro e Takahashi (2008) mostraram as posições dos enfermeiros em três categorias distintas:

a) dificuldades percebidas no processo de avaliação da aprendizagem em que a disponibilidade de tempo, sentimentos negativos quanto à avaliação e despreocupação com os resultados dos treinamentos são os desafios a serem trabalhados no dia-a-dia;

b) metodologia desenvolvida no processo de avaliação da aprendizagem, devendo considerar diferentes ritmos de aprendizado, sua experiência e história de vida e conhecimentos anteriores;

c) a avaliação do processo ensino-aprendizagem como um indicador preciso das ações passadas e controle da qualidade do ensino adotado no treinamento.

\subsection{Prática pedagógica do enfermeiro}

Esta categoria revelou que os enfermeiros professores demonstraram, de forma muito clara, a complexidade do trabalho docente, evidenciando a necessidade de comprometimento com as questões pedagógicas a fim de que ocorra uma transformação no ensino de Enfermagem, como relatado no artigo 1. Corroborando com essa afirmação, na dissertação 5 temos que esse preparo pedagógico tem que dar conta das constantes mudanças e da evolução tecnológica num mundo globalizado.

O artigo 15 retrata que a inexistência de disciplinas de cunho pedagógico, que envolvam o processo de aprendizagem embasado por teorias cognitivas sustentáveis, resulta em profissionais altamente preparados para o exercício de suas especialidades, sem atentar para a continuidade neste processo. O artigo 10, 6 e 19 sistematiza que essa prática pedagógica do enfermeiro seja realizada à luz de uma prática reflexiva. "O professor reflexivo tem como alicerce de sua prática um pensamento consciente capaz de construir e/ou reconstruir sua ação docente de forma inteligente, ativa, crítica e autônoma." (RODRIGUES; M. SOBRINHO, 2006, p. 458).

Há também uma abordagem dos recursos utilizados pelo professor enfermeiro no desenvolvimento da sua prática pedagógica, como retratada no artigo 8 e 22. "Houve uma predominância do uso de métodos ativos porque, mesmo os docentes que informaram usar as aulas expositivas, acrescentaram a interação com os alunos, o diálogo ou a liberdade para a colocação de questões," (FRIEDLANDER; MOREIRA, 2006, p. 11). Dentre os métodos, o artigo 22 destaca as construções das aulas em cima de situações reais para os alunos. Na dissertação 2 há uma proposição da proposta de Paulo Freire para mediar essa prática pedagógica do enfermeiro. $\mathrm{O}$ artigo 27 propõe Arco de Charles Maguerez como metodologia ativa.

Freo (2002) afirma que a enfermagem vem utilizando a obra de Paulo Freire, proposta como uma pedagogia libertadora e problematizadora, transformando o mundo vivido pela ação consci- 
ente, ao ler e refletir esse mundo. A vivência desta prática pedagógica permitiu desenvolver um processo de ação-reflexão-ação das atividades docentes e assistenciais exercidas por nós, a partir da aplicação do Arco de Charles Maguerez, uma construção de nossa trajetória no processo de aprender a ensinar, sistematiza Prado et al. (2012). O artigo 24 retrata que a docência em enfermagem vai da prática tradicional até as mais inovadoras. Nessa mesma perspectiva, o artigo 9, realizou uma pesquisa na influência das Práticas Educativas Emancipatórias e não Emancipatórias. Constatou-se que a Prática Educativa dos docentes encontra-se alicerçada em bases não Emancipatórias, fato ratificado pelo discurso dos discentes.

A dissertação 12 propõe dez competências para ação educativa da enfermagem. Promover a integralidade do cuidado à saúde; articular teoria e prática; promover o acolhimento e construir vínculos com os sujeitos assistidos; reconhecer-se e atuar como agente de transformação da realidade em saúde; reconhecer e respeitar a autonomia dos sujeitos em relação a suas vidas; respeitar o saber de senso comum, reconhecendo a incompletude do saber profissional; utilizar o diálogo como estratégia para a transformação da realidade em saúde; operacionalizar técnicas pedagógicas que viabilizem o diálogo com os sujeitos assistidos; instrumentalizar os sujeitos com informação adequada e, finalmente, valorizar e exercitar a intersetorialidade no cuidado à saúde. Molina e Mioto (2009) afirmam, em relação às práticas pedagógicas, que o docente enfermeiro só pode promover uma ação pedagógica transformadora da realidade se atuar de forma humana.

\subsection{Formação inicial e formação continuada}

Salienta-se que todas as produções textuais analisadas, de uma forma ou de outra, trataram sobre a formação ou refletindo esta de forma enfática ou ainda, ressaltando sua importância para o exercício da docência em enfermagem, por vezes de forma incipiente. Na formação inicial do enfermeiro docente, houve destaque para a questão das competências e habilidades requeridas para um futuro docente na área, afirmam Molina e Miotto (2009). As produções textuais 2, 4, 12, 13, 14, 18, 19, 21, 22 e 24 trouxeram de forma mais enfática a formação pautada na construção de competências, abordando, por vezes, as leis de diretrizes curriculares.

As Diretrizes Curriculares oferecem às escolas ou cursos motivações para desenvolver estratégias que estimulem as discussões coletivas para colaborar com a construção de projetos políticos pedagógicos que aproximem a formação do enfermeiro das necessidades locais de saúde, respeitando a vocação e a identidade institucional. Procedendo desta forma, estarão favorecendo a consolidação do Sistema Único de Saúde (SUS) no modelo de atenção à saúde que se fundamenta em um conceito ampliado de saúde e justiça social. Faustino et al. (2003) perceberam, pelas narrativas do seu trabalho, que os enfermeiros professores demonstram ter consciência de que o bacharelado os torna enfermeiros, e não professores e que adentrar no campo da docência exige formação específica.

No artigo 15, há um apontamento que retrata que não se deve atribuir somente à formação inicial a responsabilidade de capacitação para a ação docente, uma vez que a prática profissional aliada à educação permanente em serviço são reforçadores desta ação. O artigo 10 reforça essa afirmação, concluindo, em seus achados, que para os enfermeiros professores formarem um enfermeiro apto a atuar em todas as dimensões do cuidado como promotor da saúde do cidadão, da família e da comunidade é necessária a formação pedagógica. Backs, Moyá e Prado (2011) em trabalho, evidenciaram necessidade de contemplar, na formação inicial, aspectos pedagógicos aos enfermeiros, tomar a formação permanente como essencial diante da complexidade do conteúdo e do ensino, usar o mentoring/monitoramento e a valorização da aprendizagem com docentes experimentados, para o desenvolvimento do ensino com qualidade. 
Friedlander e Moreira (2006) afirmam que as políticas educacionais relativas à docência em enfermagem podem tomar como base os resultados desta investigação para que estimulem a evolução e as melhorias na formação desses profissionais. E, para tal, os artigos 11 e 28 sistematizam experiências sobre o preparo para a docência na pós-graduação em enfermagem. "O presente texto aborda aspectos do preparo de pós-graduandos em enfermagem para a docência, por meio do Programa de Aperfeiçoamento de Ensino (PAE), oferecido pela Universidade de São Paulo." (PIMENTEL; MOTA; KIMURA, 2007, p. 161).

"Estágio de docência é parte integrante da formação do pós-graduando, objetivando a preparação para a docência e a qualificação do ensino de graduação." (OLIVEIRA; SILVA, 2012, p.131). Backs et al. (2010) dizem que, em geral, as produções textuais analisadas confirmam que a docência requer o envolvimento efetivo e afetivo do estudante, como autor e protagonista de sua própria história. Para tanto, uma metodologia participativa estimula a criatividade e a iniciativa, e torna-se ferramenta indispensável para a atuação docente em vista da aprendizagem e da formação profissional do estudante. Assim, no caso da enfermagem, Pinhel e Kurcgant (2007) comentam que a construção das competências docentes se dá ao longo de um processo de contínua capacitação profissional de enfermagem ligado à docência, perfil este que está em constante transformação.

\section{5 | CONSIDERAÇÕES FINAIS}

As evidências teóricas e empíricas sobre a formação do enfermeiro professor semeou as seguintes reflexões: Que a categoria ainda dispõe de poucas produções científicas sobre a temática, uma vez que, de 3388 produções mapeadas, apenas $n=28$ atingiram os critérios de inclusão do estudo; há percepção, por parte dos enfermeiros, da necessidade de melhorar a sua prática pedagógica, fato positivo que demonstra a compreensão do docente enfermeiro em sistematizar processos de ensino e aprendizagem; em geral, há consenso sobre a necessidade de formação do enfermeiro para a docência. Entretanto, sistematiza-se que essas referências ainda são incipientes no que se refere à educação reflexiva e na proposição de uma prática educativa para além do mundo do trabalho, em uma perspectiva de formar pessoas para os tempos contemporâneos.

Dito isto, esta revisão integrativa sinaliza, portanto, para a necessidade de formação, seja inicial e/ou continuada, voltada ao enfermeiro docente. Mais que isso, de uma formação reflexiva, dotada de questionamentos, argumentações científicas, com espaços de liberdade, a fim de proporcionar autonomia aos sujeitos. Este estudo possui limitações no que se refere à possibilidade de generalização dos seus resultados, assim como a inclusão de outras bases de dados. 


\section{Referências}

ASTRO, L. C.; TAKAHASHI, R.T. Percepção dos enfermeiros sobre a avaliação da aprendizagem nos treinamentos desenvolvidos em um hospital de São Paulo. R. Esc. Enferm., São Paulo, v. 42, n. 2, p. 305-311, 2008.

BACKES, D. S. et al. Repensando o ser enfermeiro docente na perspectiva do pensamento complexo. R. bras. Enferm., Brasília, DF, v. 63, n. 3, p. 421-426, 2010.

BACKES, V. M. S.; MOYÁ, J. L. M.; PRADO, M. L. do. Processo de construção do conhecimento pedagógico do docente universitário de enfermagem. R. Latino-Am. Enfermagem, Ribeirão Preto, v. 19, n. 2, p. 421-28, 2011.

DEMO, P. Educar pela pesquisa. 5. ed. Campinas: Autores Associados, 2002.

FAUSTINO, R. L. H. et al. Caminhos da formação de enfermagem: continuidade ou ruptura? R. bras. Enferm., Brasília, DF, v. 56, n. 4, p. 343-347, 2003.

FREO, M. C. Reflexão sobre a prática educativa dos enfermeiros assistenciais na formação profissional. 2002. 115 f. Dissertação (Mestrado em Enfermagem) Universidade Federal de Santa Catarina, Florianópolis, 2002.

FRIEDLANDER, M. R.; MOREIRA, M. T. A. Formação do enfermeiro: características do professor e o sucesso escolar. R. bras. Enferm., Brasília, DF, v. 59, n. 1, p. 9-13, jan./fev. 2006.

GODOY, C. B. de. O curso de enfermagem da Universidade Estadual de Londrina na construção de uma nova proposta pedagógica. R. Latino-Am. Enfermagem, Londrina, v. 10, n. 4, p. 596-603, 2002.
MENDES, K. D. S.; SILVEIRA, R. C. C. P.; GALVÃO, C. M. Revisão integrativa: método de pesquisa para a incorporação de evidências na saúde e na enfermagem. Texto e Contexto Enfermagem, Florianópolis, v. 17, n. 4, p. 758-764, 2008. Disponível em: <http://www.scielo. br/pdf/tce/v17n4/18.pdf>. Acesso em: 5 ago. 2013.

MOLINA, A. A.; MIOTTO, L. B. Currículo de enfermagem: competências e habilidades para formação docente. CuidArte Enferm., Riberão Preto, v. 3, n. 1, p. 79-87, 2009.

NÓBREGA-THERRIEN, S. M. Dominação e resistência no trabalho da enfermeira. R. bras. Enferm., Brasília, DF,, v. 54, n. 3, p. 420-426, 2001.

OLIVEIRA, M. L. C. de; SILVA, N. C. da. Estágio de docência na formação do mestre em enfermagem: relato de experiência. Enfermagem em Foco, Salvador, v. 3, n. 3, p. 131-134, 2012.

PIMENTEL, V.; MOTA, D. D. C. F. de.; KIMURA, M. Reflexões sobre o preparo para a docência na pós-graduação em enfermagem. R. Esc. Enferm., São Paulo, v. 41, n. 1, p. 161-164, 2007.

PINHEL, I.; KURCGANT, P. Reflexões sobre competência docente no ensino de enfermagem. R. Esc. Enferm., São Paulo, v. 41, n. 4, p. 711-716, 2007.

PRADO, M. L. et al. Arco de Charles Maguerez: refletindo estratégias de metodologia ativa na formação de profissionais de saúde. Esc. Anna Nery, Rio de Janeiro, v. 16, n. 1, p. 172-177, 2012.

RODRIGUES, M. T. P. R.; M. SOBRINHO, J. A. C. Enfermeiro professor: um diálogo com a formação pedagógica. R. bras. Enferm., Brasília, DF, v. 59, n. 3, p. 456-459, 2006.

Obstáculos didáticos no cotidiano da prática pedagógica do enfermeiro professor. R. bras. Enferm., Brasília, DF, v. 61, n. 4, p. 435-440, 2008. 